\title{
La increíble empresa de Sarmiento de Gamboa y su triste fin: Posibles causas de la tragedia en el Estrecho de Magallanes en el siglo XVI
}

\author{
JUAN PABLO ESPINOZA G., RICARDO ESPINOZA G.
}

Facultad de Medicina. Universidad de los Andes.

Recibido el 29 de junio de 2010, aceptado el 25 de octubre de 2010.

Correspondencia a: Dr. Ricardo Espinoza G. Facultad de Medicina, Universidad de los Andes. Fax: 2141752 E-mail: respinoza@uandes.cl

\section{The possible causes of the tragedy of "Port Famine" in the Strait of Magellan}

The attempts to colonize the Strait of Magellan soon followed the discovery of this route. Pedro Sarmiento de Gamboa, a Spanish sailor, established human settlements to fortify those lands and control the transit of vessels, especially those of English corsairs, which devastated Chilean and Peruvian coasts. During the summer of 1584, approximately 500 soldiers, artisans, priests, women and children established two villages called "Nombre de Jesús" and "Rey Don Felipe". From the beginning, these settlers had leadership and communication problems and difficulties to obtain food. After three winters only 17 to 18 people survived according to the testimony of one of the survivors, that was rescued by an English sailor named Cavendish, which renamed the village "Rey Don Felipe" as "Port Famine". When he observed the scenes of abandonment and death, he supposed that the settlers died due to lack of food. Other factors that facilitated the desolation were hypothermia, execution, anthropophagy and lesions caused by natives. There is also a possibility that intoxication by red tide (harmful algal bloom) could explain in part the finding of unburied corpses in the the strait beaches.

(Rev Med Chile 2010; 138: 1456-1460).

Key words: Chile; Harmful algal bloom; Starvation.
L os poco más de 400 años transcurridos desde que Pedro Sarmiento de Gamboa intentara asentamiento en las riberas del Estrecho de Magallanes no restan dramatismo al hecho de que, al cabo de tres inviernos, este primer esfuerzo fundacional hispánico en un lugar tan remoto terminara con la muerte de casi todos, excepto unos poquísimos, quizás dos personas. Se ha repetido que la causa fue la carencia de alimentos, desde que se conociera la versión inglesa formulada por Thomas Cavendish, quien dio por llamar Puerto del Hambre (Port Famine) al poblado Rey Don Felipe.

El objetivo de este trabajo es repasar los relatos que conducen, en 1584, al establecimiento de una Gobernación en el Estrecho de Magallanes y postular otras alternativas que, al menos parcialmente, expliquen la masiva mortalidad que acompañó al intento.

Los hechos nos han llegado por el relato del propio Sarmiento y los análisis más relevantes sobre dicha epopeya de los historiadores Mateo Martinic $^{1}$ y José Miguel Barros ${ }^{2}$. También revisamos el primer testimonio de Tomé Hernández ${ }^{3}$, un sobreviviente rescatado por Cavendish, quien hiciera su primera declaración ante el Gobernador de Chile, en 1587. Se revisó la evidencia científica actual para sostener las hipótesis planteadas. 


\section{Referencias históricas}

A poco del descubrimiento del Estrecho de Magallanes, las costas de Sudamérica sufrían las incursiones de corsarios ingleses, que asolaban puertos y poblados. A ello se suma que, pese a que el Pasaje de Drake, al sur del Cabo de Hornos había sido descubierto en 1525, los difusores de la cartografía seguían destacando al estrecho como el pasaje más austral entre el Mar del Norte (Océano Atlántico) y el Océano Pacífico, y que, por tanto, separaba a América de la Terra Australis Incognita ${ }^{4}$.

Por tanto, se justificaba la necesidad de que en los accesos al estrecho se estableciesen colonias y fortificaciones que custodiaran el flujo de embarcaciones. Tal idea fue concebida y alimentada por su afán aventurero y conquistador, en la mente del navegante español don Pedro Sarmiento de Gamboa. Nacido en 1532, había conocido en Galicia los secretos de la navegación y era estimado grandemente por el Virrey del Perú ${ }^{2}$. Conocedor de idiomas, cosmografía, astronomía, también historiador, había escrito una crónica sobre la conquista y pueblos del antiguo Perú. Viajó a España para solicitar directamente de Felipe II los recursos necesarios para tan digna como magna empresa. En 1580, Sarmiento había explorado el estrecho y tenía una cercana idea de la zona; el actual desafío, poblarlo, tenía aparejado su nombramiento como Gobernador y Capitán General del mismo, sub conditione, es decir, siempre que la misión fuese cumplida y que, efectivamente, se poblaran esas australes latitudes.

Para pesar de Sarmiento, la corona española designó como conductor de la expedición a Diego Flores de Valdés. No obstante, apoyó fielmente el proyecto. La flota zarpó de Sevilla en septiembre de 1581, con 23 navíos y casi tres mil personas a bordo, entre las que se contaban, además de los soldados, colonos propiamente tales, incluidas 13 mujeres y diez niñas y niños, gran variedad de artesanos, herreros, y dos frailes franciscanos. Tras un primer infortunio y cuantiosas pérdidas por un temporal se retardó la salida final tres meses y se redujo la flota a 16 navíos. La primera recalada fue Río de Janeiro. Un primer intento por acceder al estrecho a comienzos de 1583 terminó con el desistimiento de Flores de Valdés y su regreso a España. A fines del mismo año dos naos, Santa María de Castro y Trinidad, y tres fragatas tomaron nuevamente rumbo sur. La primera aproximación a la boca oriental la hicieron en febrero de 1584. Con mal tiempo y observados por los indígenas, embocaron el estrecho en el cuarto intento. Llegaron con Sarmiento unas 529 personas. Desembarcaron próximos a Punta Dungeness y el 11 de febrero de 1584 se estableció el primer poblado: Nombre de Jesús. Con pie en tierra firme, Sarmiento proclamó su discurso de posesión y levantando el altar mayor entonó el Te Deum y el Vexilla Regis ${ }^{5}$. El relato de Tomé Hernández ${ }^{3}$ nos ha transmitido que tenían bastimentos para unos cuatro meses, entre ellos algunos animales y variadas semillas.

La aridez del lugar, escasez de agua y el primer contacto con los indios en que hubo heridos, pudieron motivar a Diego de la Rivera, nuevo Almirante de la flota, a que también se regresase, sin comunicárselo a Sarmiento. Este último decidió que la nave restante, la Santa María de Castro siguiese explorando el Estrecho en busca de la conocida Punta Santa Ana donde desembocaba el río San Juan y él, con otro grupo, seguiría marcha al occidente caminando por el litoral. Trágico trayecto, en que sin calzado, escasos alimentos y con nuevos ataques de los lugareños, experimentaron varias bajas. Veiga ${ }^{5}$ nos refiere: "El viaje por tierra fue una marcha que bien se puede calificar de atroz. Ya a los pocos días caminaban descalzos porque las alpargatas se rompieron de podridas que estaban... con los pies sangrantes e hinchados, la gente se desanimaba y se quejaba”. Además, "Gran trabajo fue continuar la marcha con los heridos y la gente hambreada y cansada...y así empezó a sacrificar las siete cabras de crianza que llevaba... asaba un cuarto y lo repartía a bocado por hombre, manjar que a partir del segundo día fue solamente para los heridos. De los perros que traían, tres desaparecieron y dos se los comieron a escondidas", nos ha dicho el mismo Veiga ${ }^{5}$. Finalmente, $y$ tras avanzar unos $300 \mathrm{~km}$ por tierra, ambos grupos se encontraron y fundaron a finales de marzo, en la actual Bahía de San Blas, el segundo asentamiento: Rey Don Felipe. Allí quedaron algunos y Sarmiento intentó regresar a Nombre de Jesús, pero los vientos lo sacaron del Estrecho sin poder volver a entrar. Corría el mes de mayo de 1584, y Sarmiento decidió regresar a Río de Janeiro en busca de socorros locales. Finalmente, en 1586 dispuso su vuelta a España, casi dos años después de haber dejado su Gobernación ${ }^{5}$. En la travesía cayó prisionero de los ingleses y no pisó suelo español sino hasta 1590, donde se presentó "tullido, encallecido y sin dientes". 
Pues bien, demorándose el regreso de los exploradores del estrecho, el capitán a cargo de Nombre de Jesús, Andrés de Biedma, separó a otros 40 para que fueran también por tierra estrecho adentro; como resultado, más muertes. Tomé Hernández relató que de los cinco sobrevivientes, uno fue asesinado por los otros y practicaron el canibalismo. Estos fueron ajusticiados, al igual que otro, por amotinamiento. Hacia fines de 1584 fue el mismo Biedma el que salió en busca de los demás, quedando ya menos de 100 habitantes en Nombre de Jesús donde se habían decretado otras ejecuciones. Antes de que se cumpliera un año y próximos al siguiente invierno, los restantes también abandonaron Nombre de Jesús. Han debido encontrar un sendero de cadáveres antes de reunirse en Rey Don Felipe, con ya escasos sobrevivientes. Intentaron de salir de allí, unos por tierra, otros por mar, para lo que construyeron unos bateles, pero ambas iniciativas fracasaron. Ante esto, algunos decidieron quedarse en la costa de Santa Brígida y otros repoblar Rey Don Felipe. La situación era desesperada. Para fines de 1585 o comienzos de 1586 reintentaron salir por mar en una nueva embarcación, navegando equivocadamente hacia el mar de Otway, lo que los obligó a regresar ${ }^{1}$. Aquel invierno de 1586 no quedaban más que 21 ó 18 personas, sin consideramos la primera o la segunda versión de Hernández. Estas, incluidas tres mujeres, vagaban por las costas del estrecho, y resistieron hasta el verano siguiente. En los primeros días de 1587 avistaron naves tratando de entrar al estrecho. Iban con Thomas Cavendish a la cabeza. Un grupo intentó hacer contacto y, lo que no ha quedado nunca aclarado por qué, es que sólo Tomé Hernández fue el que subió a bordo de una nave inglesa marchándose con ellos, sin que regresaran por los demás. Al pasar por Rey Don Felipe, este navegante se aprovisionó de agua y leña, aprovechando de llevarse las piezas de artillería ${ }^{3,5} \mathrm{y}$, observando las escenas de abandono y de muerte, "con tantos cadáveres sin enterrar e inficionados" dio por llamar a aquel lugar Puerto del Hambre.

\section{Análisis de las posibles causas de muerte de la población colonizadora}

Estas serán expuestas sin seguir un orden de magnitud en cuanto a lo que pudieron pesar en la tragedia relatada.

\section{A. Muerte por desnutrición}

Todos los relatos históricos enfatizan que la falta de alimentos fue crítica y la consecuente desnutrición una de las principales causas de muerte de los colonizadores. Está planteado en las cartas de Sarmiento y es lo dicho por los sobrevivientes. Como ejemplo, Hernández escribió: "La dicha gente y el dicho Sargento volvieron en seguimiento del dicho navío y no pudieron llegar porque fue mucha la nieve que les cayó y ya faltó la comida porque no la tenían. Y perecieron todos de hambre...". La misma necesidad la relata Alonso Veiga en sus comentarios ${ }^{5}$, cuando refiere que sacrificaron las cabras de crianza y aun los perros que llevaban. Pues bien, sabemos que la falta crónica de alimentos conduce a una malnutrición calóricoproteica que moviliza todas las reservas grasas y musculares. Para un hombre de contextura normal, significa recurrir a 15 a $25 \%$ de energía de reserva como grasa, unos 15 kilos, que se consumen en unos dos meses. Como esta reserva es algo mayor en la mujer, se puede observar en ellas una sobrevida también mayor. Cuando esta pérdida de masa lleva a un peso inferior a $70 \%$ del peso ideal, disminuye la inmunidad celular y aumenta el riesgo de infecciones, hay dificultad para deambular y aparecen progresivamente signos cutáneos y mucosos por la carencia de vitaminas y elementos trazas. Cuando la pérdida sobrepasa el $50 \%$ del peso ideal hay desorientación y muerte ${ }^{6}$. Trabajos realizados por arqueólogos y biólogos $\operatorname{argentinos}^{7}$ sobre osamentas de Nombre de Jesús, han documentado que en todos los esqueletos adultos se observa signos de osteopenia, buen indicador de desnutrición. Este hecho, sin embargo, no asegura que el proceso se haya desarrollado sólo en esa localidad austral, donde permanecieron no más de diez meses; es probable que estos hombres de mar o colonizadores hayan sido, además, individuos carenciados crónicamente. Por otro lado, si bien Tomé Hernández refirió que: "Y que ellos sembraron trigo, cebada y habas. Y que el trigo no granó y la cebada granó y no se secó porque no hubo tiempo. Y que las habas granaron y no se secaron y siempre estuvieron verdes y estuvieron antes de salir seis meses debajo de la nieve", no es menos cierto que los lugareños se procuraban alimento, y la caza de ganado era algo habitual. Además, se habían dado cuenta de la existencia de "uvas de espino" (calafates) y "alverjones" (arvejilla), lo que junto a mariscos como los mejillones, 
contribuyeron a su sustento ${ }^{5}$. También los lobos de mar les procuraron alimento ${ }^{1}$. Sin embargo, dadas las condiciones locales y el desconocimiento de la zona, es probable que a los pobladores se les haya dificultado conseguir alimento en cantidad suficiente y en forma estable, por lo que una de las principales causas que contribuyeron al debilitamiento y muerte creemos que ha sido, efectivamente, la escasa alimentación. Esta causa sería especialmente válida en los largos períodos invernales donde el procurarse comida estaba más limitado. Así lo vuelve a decir Hernández : "Esperando la vuelta de Sarmiento hasta cinco meses, padeciendo de necesidad de ración a cinco onzas de bizcocho a cada soldado; y que al cabo de los cinco meses, que fueron de invierno, habiendo perecido alguna gente de hambre..."

\section{B. Muerte por ajusticiamiento}

Los relatos han sido claros en cuanto a que en varias ocasiones los capitanes han debido decretar ajusticiamiento $^{1,5}$. En las relatadas condiciones de colonización, la insurgencia ha debido ser considerada muy grave, dado el efecto de disgregación sobre la población y por lo mismo, era castigada con la pena de muerte.

\section{Muerte por homicidio y otros hechos violentos}

Es claro el relato de Hernández ${ }^{3}$ que se cometió homicidio con el fin de practicar canibalismo. También, que cuando Sarmiento partió por tierra estrecho adentro, han debido abandonar a un herido que no quiso seguir caminando. También están los relatos, numerosos, de ataques por los indios. En la crónica de Martinic ${ }^{1}$ leemos: "a partir de entonces la marcha se vio dificultada tanto porque debió curarse y atenderse a los heridos que sumaban diez hombres, y ayudárseles a caminar, cuanto porque se temía un nuevo ataque indígena" ${ }^{\text {. Veiga }}{ }^{5}$ señala: "Entre los españoles hubo diez bajas: un muerto por una flecha que lo atravesó desde la espalda a la tetilla del corazón, y nueve heridos, de los cuales uno murió en el camino y otro se quedó a morir entre unos calafates". A esto podemos sumar la posibilidad de que en Rey Don Felipe, ya en las etapas finales, la extrema necesidad haya volcado los espíritus a prácticas violentas con el fin de retener lo poco que tenían. Se puede sumar como argumento que Cavendish encontró numerosos cadáveres sin enterrar, ¿sería ello producto de la misma violencia?, porque también se puede plantear que la extrema debilidad de los sobrevivientes haya imposibilitado la práctica funeraria, conducta tan propiamente humana.

\section{Muerte por hipotermia}

Definida la hipotermia como una temperatura central menor a $35^{\circ} \mathrm{C}$, sabemos que con menos de $28^{\circ} \mathrm{C}$ es grave y altamente mortal si no es corregida oportunamente ${ }^{8}$. Pues bien, el clima de la Península de Brunswick, cerca de Punta Arenas, ya próxima a la latitud $60^{\circ}$ sur, es del tipo trasandino con una temperatura media es de 6 a $7^{\circ} \mathrm{C}$, pero en los meses entre junio y agosto ésta no sobrepasa los $0^{\circ} \mathrm{C}$. A esto deben sumarse los frecuentes vientos de predominio suroeste y oeste ${ }^{9}$. La población colonizadora, presumiblemente desnutrida ha debido tolerar peor las bajas temperaturas, justamente por su incapacidad para generar calor. Hay que sumar el precario abrigo y los vientos descritos que aumentan las pérdidas de calor por convección. En estado de hipotermia, disminuye el flujo cerebral y renal, se altera de actividad cardíaca y se producen apneas que conducen a la muerte ${ }^{10}$. Es muy probable que, al menos en algunos casos, la hipotermia haya sido la causa determinante de la muerte.

\section{E. Muerte por intoxicación}

Una observación que abre esta posibilidad la observamos en el texto de Veiga ${ }^{5}$, cuando dice: "Encontraron en los árboles unos racimos de agallones (agallas del roble) verdes, blandos y de sabor de castañas, que los soldados hallaron sabrosos y los comieron como pan, con el resultado que a muchos les cayeron como piedras en el estómago y se les hinchó la barriga a reventar". No sabemos si lo descrito fue causa de muerte. Sin embargo, una posibilidad de intoxicación mortal está dada por la "marea roja". Esta corresponde a un fenómeno natural de causa desconocida debida al aumento de ciertas microalgas unicelulares, especialmente del tipo de los dinoflagelados, que componen el plancton marino ${ }^{11,12}$. Debido a los pigmentos que poseen, este aumento de organismos puede determinar cambios de color del agua, lo que ha generado su nombre vulgar. Algunas de estas algas pueden producir toxinas, que, concentradas por moluscos bivalvos como los choros, almejas, 
machas, ostiones y ostras llegan en gran cantidad a quienes los consumen, de ahí que a la marea roja se le conozca como floración de algas nocivas (FAN). Se conocen varias de estas toxinas; la de efecto más grave es la saxitoxina. Corresponde a una toxina neuromuscular que, en un lapso de minutos a pocas horas, puede producir la muerte por parálisis respiratoria. Conocida como toxina paralizante; corresponde a una tetrahidropurina que bloquea selectivamente el transporte de sodio a nivel de la membrana celular. La Alexandrium catenella es la principal especie de dinoflagelado productor de esta toxina. En Chile, el fenómeno de marea roja está ampliamente extendido ${ }^{13}$ y el primer registro de una FAN data de 1827; más, es perfectamente posible que en Magallanes hubiese estas floraciones en etapas previas, como la época del asentamiento de los colonos a los que nos hemos referido. Siendo fenómenos periódi$\cos$, es probable que los individuos originarios conociesen de su existencia y que, por tanto, afectara especialmente a los colonizadores. La teoría planteada puede explicar la muerte de tantos de ellos y el hallazgo de osamentas sin enterrar; los sobrevivientes pudieron intuir una suerte de intoxicación por la rápida aparición de síntomas como naúseas, mareos, dificultad para movilizarse, hablar y respirar, hasta llegar a la muerte.

Como conclusión queremos plantear la multicausalidad del triste desenlace de la empresa de colonización emprendida por Pedro Sarmiento de Gamboa en las riberas del Estrecho de Magallanes en la segunda mitad del siglo XVI, y hacer notar otras causas de muerte no consideradas en la literatura. No corresponde enjuiciar ni las motivaciones ni la actuación de Sarmiento.

Agradecimientos: Los autores agradecen al Dr. Max Buchheister R. los interesantes comentarios sobre las posibles causas que provocaron el desenlace de esta colonización.

\section{Referencias}

1. Martinic BM. El Reino de Jesús. La efímera y triste historia de una gobernación en el Estrecho de Magallanes (1581-1590). Ans Inst Pat 1983; 14: 9-32.

2. Barros JM. Pedro Sarmiento de Gamboa. Avatares de un caballero de Galicia. Editorial Universitaria, Santiago, Chile, 2006.

3. Barros JM. Primer Testimonio de Tomé Hernández sobre las fundaciones hispánicas del Estrecho de Magallanes. Ans Inst Pat 1978; 9: 65-75.

4. Kirkpatrick FA. Los Conquistadores Españoles. Ediciones Rialp, SA., Madrid, España, 2004.

5. Veiga Alonso J. El Puerto del Hambre. Biblioteca Virtual Miguel de Cervantes. Disponible en http://www. cervantesvirtual.com/servlet/SirveObras/058183632 99492706317857/p0000001.htm [Consultado el 08 de noviembre de 2006].

6. Halsted $\mathrm{CH}$ H. Malnutrition and Nutritional Assessment. En: Harrison. Principles of Internal Medicine. $16^{\text {th }}$ edition. Mc Graw-Hill Companies, Inc, 2005. p. 411-5.

7. Guichon RA, Suby JA, Casali R, Fugasa MH. Health at the time of Native-European contact in Southern Patagonia. First steps, results, and prospects. Mem Inst Oswaldo Cruz 2006; 101 (Suppl. II): 97-105.

8. Danzl DF. Hypotermia and Frosbite. En Harrison. Principles of Internal Medicine. $17^{\text {th }}$ edition. Mc Graw-Hill Companies, Inc, 2008. p 135-8.

9. Dirección Meteorológica de Chile. Dirección General de Aeronaútica Civil (DGAC), Chile. http://www.meteochile.cl [ Consultado el 08 de noviembre de 2009]

10. Wilson RF. Handbook of Trauma. Lippincott Williams and Wilkins, 1999.

11. Smayda TJ. Adaptative view ecology, growth strategies and global expansion of dinoflagellates. J Oceanogr 2002; 58: 281-94.

12. Hallegraeff GM. Harmful algal blooms. A global overview. En: Manual on harmful marine microalgae. Hallegraeff GM, Cembella AD, eds. UNESCO. París, Francia, 2003. p 25-49.

13. Rodríguez L. Revisión del fenómeno de Marea Roja en Chile. Rev Biol Mar 1985; 21: 173-97. 